\title{
Impact Assessment of Long-Term Work Zones in Arterial Roads on Commercial Activities in Dammam Metropolitan Area, Saudi Arabia
}

\author{
Nawaf M. Alshabibi and Hatem T. Abdelhamid* \\ Department of Urban and Regional Planning, Faculty of Architecture and Planning, \\ Imam Abdulrahman Bin Faisal University, Dammam, Saudi Arabia \\ htabdelhamid@iau.edu.sa*
}

\begin{abstract}
This paper assesses the impact of long-term work zones in arterial roads on commercial activities in Dammam Metropolitan area. The study focuses on two cases of long-term work zones in arterials in two major cities in Dammam Metropolitan Area. The first case is a work zone with full lanes closure on Prince Mohamed Bin Fahad Road at the south east entrance of Dammam city. The second case is a work zone with full lanes closure on King Abdul-Aziz Road at the northern entrance of Al-Khobar City. Data collection relies on field survey including questionnaires to affected business owners and managers. The questionnaire has been developed to assess the impact before and during road works period, in the work zone, on mobility and accessibility to commercial activities. Field survey includes 201 commercial activities at two work zone locations. Answers have been registered in Excel spreadsheet. Data analysis includes percentages of change, means, and standard deviation of dependent variables before and during the presence of the work zone. It was found that long-term work zones on arterials have multiple negative impacts on workers, sales, and customers. These impacts are related to lack of mobility, accessibility and reduction of parking availability during work period. Also, restaurants and travel agencies were the most effected activities by work zone presence, while banks were the least effected.
\end{abstract}

Keywords: Long-term work zones, Lane closures, Arterial roads, Dammam Metropolitan Area, Saudi Arabia.

\section{Introduction}

The increase of motor vehicle in Saudi Arabia is divided into thirteen provinces. One of them is the Eastern province. During the last decade, The Authority of the Eastern Province (EP) (Amanah) conducted many transportation projects in Dammam Metropolitan Area (DMA). These projects included operation, maintenance, and re-asphalting for many of major and arterial roads. In 2013, Amanah conducted nine transportation projects: Eight for maintenance and one for operation. The projects covered 3540 kilometers and 56 million square meters of roads in DMA. The total cost of the projects was 55 million Saudi Riyals including re-asphalting and sidewalk construction in several districts ${ }^{[1]}$. Nowadays Amanah is constructing many overpasses and underpasses to enhance mobility and accessibility to different parts of DMA. The construction process requires partial or complete lane closure on arterial roads. The closed area is occupied as a work zone (WZ). The partial lane closures require closing part 
of one lane or closing one of two lanes without changing traffic direction. Full lanes closure requires closing all lanes and detour traffic to side collector or local roads. The area occupied for projects workers and dedicated to implement the project called WZ. Short-term WZs occupy dedicated area on the road for several hours or days. Long-term WZs occupy dedicated area on the road for several months or years. In the local urban context in the Kingdom of Saudi Arabia, commercial use is directly accessible from arterial roads, Figure 1 shows characteristics of WZs on arterials in DMA where data have been collected.

Local roads are these links of transportation network that provide accessibility to local housing units by private vehicles. Speeds on local roads cannot exceed more than $25 \mathrm{~km} / \mathrm{h}$. Collector roads are these roads that collect vehicular traffic from local roads and provide mobility and accessibility to arterial roads and vice versa. Collector roads speed varies from 25 to $60 \mathrm{~km} / \mathrm{h}$. Arterial roads are these links of transportation networks that connect major parts in urban areas to provide mobility and accessibility to highways and freeways that guide the traffic out of the city. Speeds on arterials can be from 80 to $110 \mathrm{~km} / \mathrm{h}$. Figure 1 shows the classification and photos of the location of the studied WZs.

\subsection{Problem Identification}

The problem of the study is the lack of consideration of negative impact associated to WZs presence on arterials. Work zones on arterial roads in Saudi Arabia have negative impacts on mobility, accessibility, and trade. Prediction models of impacts of transportation maintenance, operation, and construction projects on arterials are seldom. Increasing the duration of projects on arterials increases the intensity of the local negative impacts.

\subsection{Study Goal}

This study focuses on the impact of work zone presence on the road way. It has two major goals. The first is to quantify local impacts of long-term (WZs) in arterials roads in Dammam Metropolitan Area on trade, mobility and accessibility of commercial activities (CA). This goal demonstrates the impacts on customers' mobility and commercial land use accessibility.

The second goal of the study is to provide solutions and suggestions to planning and transportation officials to mitigate the negative impacts of work zone presence on arterials on commercial activities.

The study doesn't focus on local changes on urban land use pattern and commercial land use relocation. Also, it doesn't look at changes on traffic operation such as level of service and capacity.

The study operational objectives or "work plan" could be summarized in the following steps:

(1) Reviewing literatures related to impacts of (WZs) on different aspects of built environment;

(2) Developing and designing the questionnaire for data collection and field survey;

(3) Conducting the field survey by a group of surveyors from 20/2/2018 until $20 / 5 / 2018$ before the opening of $\mathrm{WZ}$ in $\mathrm{Al}$ Khobar at the end of June;

(4) Entering Data in Excel Spreadsheet;

(5) Analyzing data and summarizing of percentages, means, and standard deviation;

(6) Writing study findings and conclusions.

\subsection{Study Methodology and Tools}

To collect data, the study relies on field surveying and interviewing owners and 
managers of CA. Study data has been collected through a questionnaire that has been developed with certain specific factors required to accomplish study goal. Field survey has been conducted from 20/2/2018 until $20 / 5 / 2018$ by a group of field surveyors. The entire field survey was conducted before the end of the lane closure period in AlKhobar (end of June 2018). The survey included 201 commercial activities around the 2 WZs. The questionnaire included 70 questions classified into three categories. The first category contains 20 questions about characteristics of CA such as type, area, years at the location, and sales. The second category contains 35 questions about changes on sales, number of customers, number of workers, number of parking lots, and monthly rent. Third category included 15 questions about general opinions, suggested solutions and recommendations. Answers were registered in Excel spreadsheet for data entry and analysis of percentages, means, and standard deviations before and during WZ presence.

\subsection{Study Scope}

The study covers in its geographical scope cities of Dammam Metropolitan Area (Dammam, Khobar, and Dhahran) in The Eastern Province of The Kingdom of Saudi Arabia as shown in Fig. 2. DMA contains multiple arterial roads to connect the three cities: Dammam Khobar and Dhahran.

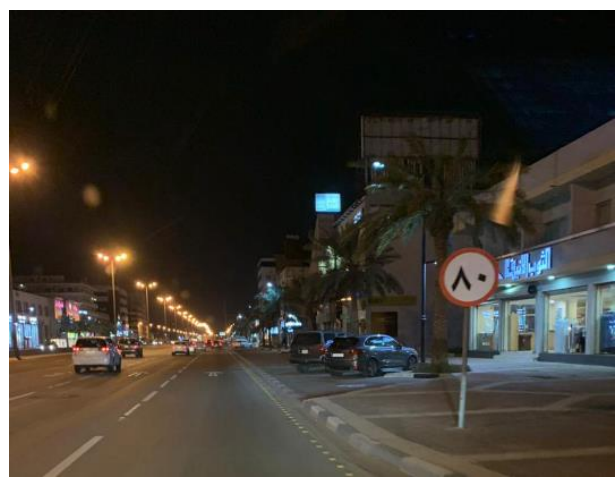

b. Speed limit on arterial at WZ 2

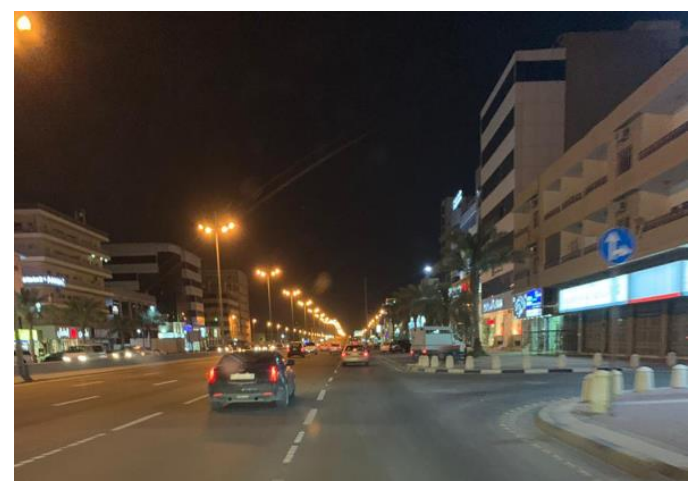

d. Commercial activities directly accessible from arterial at $\mathrm{WZ} 2$

Fig. 1. Characteristics of WZs on arterials in DMA. 


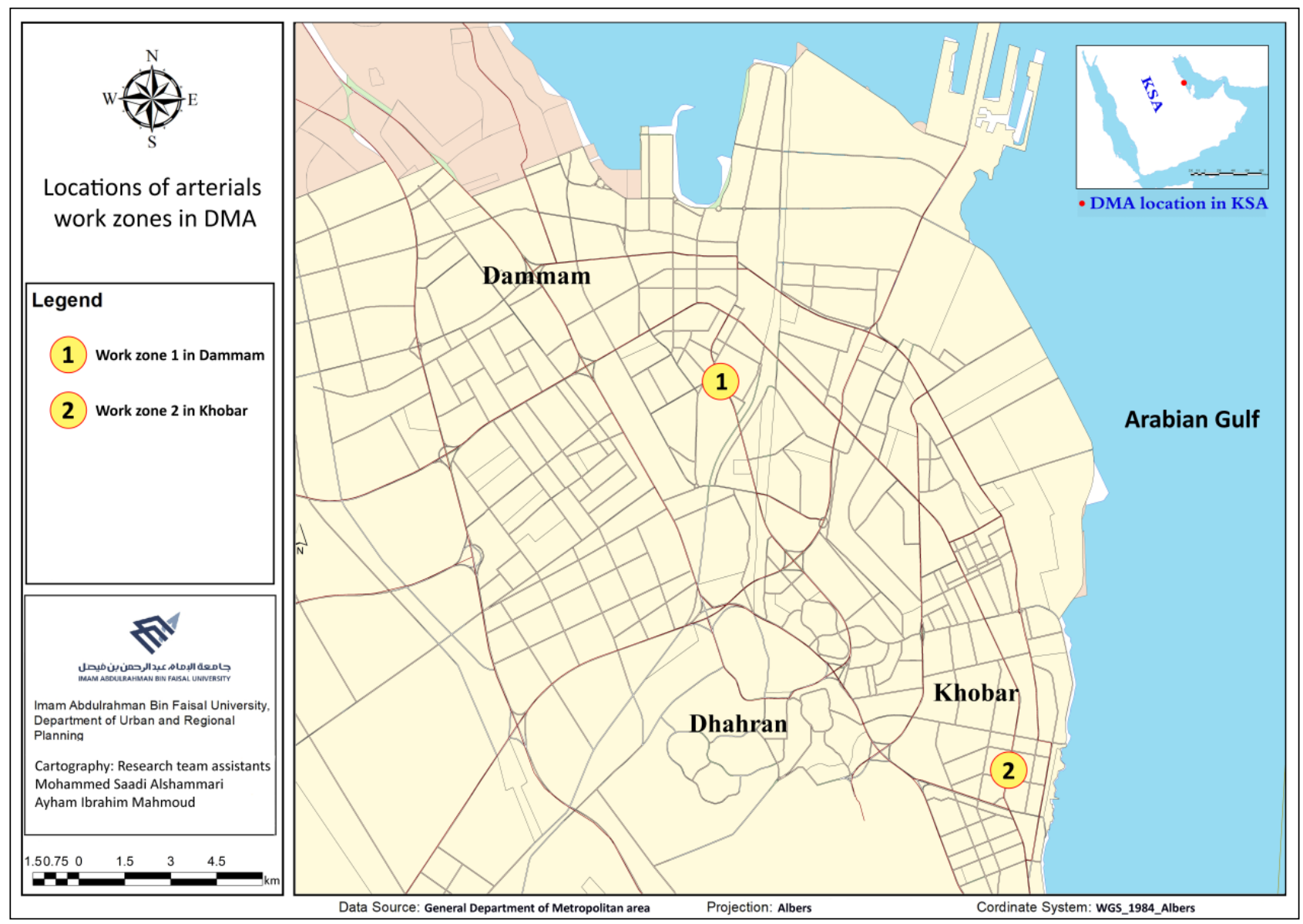

Source: Prepared by the research team, GIS data source: General Department of DMA.

Fig. 2. Studied work zones locations in DMA.

The study thematic scope is assessing and quantifying impacts of long-term full lanes closure as WZs in arterial roads on CA. The study assesses the impact by collecting data before and during the presence of WZs on both sides of arterial roads. Study time framework covers all WZs on arterials in DMA until 2018.

The study considers two cases of longterm WZs in DMA. First case is located on Prince Mohamed Bin Fahad Road, a 1.08 kilometers zone at the east-south entrance of Dammam city. Second case is on King Abdelaziz road at the northern entrance of AlKhobar City, a 2.02 kilometers zone. Figure 2 shows the location of the two studied WZs.
The study includes all commercial activities on both sides of the studied WZs. The study includes the commercial activities on ground level and upper levels of buildings. Also, the study includes productive and service commercial uses, retail and wholesale.

\subsection{Study Contributions}

The study outcomes provide several benefits/contributions, which are:

(1) Calibrating theoretical, mathematical, and simulation models to quantify impacts of transportation projects in Saudi Arabia;

(2) Predicting the impacts of WZs on CA for upcoming projects; 
(3) Providing suggested plans, strategies and solutions to mitigate negative impacts of WZs on arterial roads and increase benefits of positive impacts based on business owners and managers' recommendations;

(4) Providing plans and strategies to reduce the duration of transportation projects.

\section{Literature Review}

This part of the study reviews literatures related to lane closures and WZs impact assessment. This review includes different locations of WZs on freeways, arterials, collectors, and local roads. Also, it includes closing lanes for maintenance, operation, and construction transportation projects.

Transportation projects differ in cost, duration, and WZ configuration according to purpose. There are three purposes for transportation projects, namely construction, operation, and maintenance. Construction projects are building overpass, underpass, new routes and roads, and sidewalks. Operation projects could be manhole excavation, preparation of toll collection plaza, and installation of smart transportation equipment (ITS). Majority of maintenance transportation projects are re-asphalting part of existing road. These projects are fundamental to enhance the overall economy, mobility, and accessibility of goods and services. While constructing transportation projects, many developed countries prepare studies to assess impacts of changes in transportation system on regional and local levels. The studies determined positive and negative impacts on effected local areas and regions. Transportation officials use studies outcomes to increase benefits of positive impacts and reduce intensity and duration of negative impacts. Providing financial support directly to affected society could be one of the solutions. However, the literature shows that it is not legally simple to implement direct compensation to businesses in WZs. If the businesses were notified of the road closure and the announced closure dates were respected, businesses are not eligible for financial compensations ${ }^{[2]}$. Yet, authorities manage to find ways to provide affected businesses with financial compensation ${ }^{[2]}$.

Many studies in developed countries quantified impacts of WZs in arterial roads and freeways on urban land use pattern. Other studies focused on environmental impacts assessment of transportation project. These studies developed different theoretical methodologies to prepare manuals for different impacts assessment. The impact assessment manuals have different methods of data collection, analysis and synthesis, and for preparation of outcomes. For example, the economic impact assessment manual prepared by Department of Transport in the United Kingdom includes clear methodology to assess economic impacts of transportation projects ${ }^{[3]}$. Similar manual prepared in United State of America to predict possible impacts ${ }^{[4]}$. The two manuals provide anticipated economic impacts evaluated by general public. The public evaluation of transportation projects includes evaluating the need for transportation projects and the expected possible outcomes $[3,4]$.

Over the last decade, the main concern of transportation studies is the economic impact assessment of transportation projects on national and regional levels. National and regional transportation construction projects could be regional rail lines, highways, airports, and toll collection on regional highways. These studies focused on economic impacts associated to the increase in flow between cities and regions. Transportation projects and solutions such as providing alternative modes of transportation or alternative paths assist economic activities and investments on regional and national levels. These 
investments foster job creation and increase flow of goods and services to accessible regions. On regional level, economic impact assessment studies focus on comparing the existing conditions before and after development. Assessing the impact provides an assessment for long-term periods up to 20 years. Most dependent variables in the studies are changes in job opportunities, changes in revenues, changes in type of jobs, changes in real estate and land prices, and appearance of new economic activities on new roads. Economic impact assessment studies relied on three tools for data collection. The first tool is interviewing owners of CAs surrounding transportation projects. The second is customers' field survey and the third is Truck Origin-Destination Survey (OD survey).

Economic impact assessment studies rely on economic models for data analysis to estimate economic benefits and returns to activities during projects. Transportation planning studies include transportation models for trip generation and distribution. Data collection in these studies include socioeconomic demographic characteristics, jobs and income, transportation network characteristics such as infrastructure, level of service, and demand. Data have to be collected, and models have to be calibrated for population and goods such as trip rates, origins and destinations, and route choice. A good example is the study of regional impacts of The English Tunnel between United Kingdom and France ${ }^{[5]}$. The study showed that the existing tunnel reduces costs of mobility between European countries and United Kingdom. Another similar study is the study of (US-101) closure. It included assessing economic impacts of arterial road closure connecting California with surrounding areas in United States of America. The study produced impact assessment model of tourism generation, production, and attraction from tourism facilities on the road. The study provided suggested alternative route of the closure ${ }^{[6]}$. Also, In Auckland New Zealand, a study quantified the impacts of applying toll collection on freeways and highways ${ }^{[7]}$.

The Federal Highway Administration in United States of America found that closing lanes to occupy dedicated WZ has many advantages. Reducing transportation projects periods from 70 to $80 \%$ is the main advantage of lane closures. Lane closures enhance traffic safety for users and workers and increase workers productivity by occupying the required areas for work on the roadway. Even though, activities around the WZ are negatively impacted during lane closures. This is because of the WZ configuration reduces accessibility and mobility around working areas. Thus, regular and walking customers are looking for other accessible areas for shopping [8].

A study by Boarnet [9] conducted to assists in reducing economic impacts on commercial land uses during 1994 earthquake in Los Anglos. The study methodology included field survey of industries and retail centers at 3 different areas. The field survey of the study conducted by collecting data about physical losses associated to damages in transportation infrastructure and reduction in income. The study found significant impacts on retail and wholesale activities related to delays in freight delivery.

A study by Buffington and Wildenthal ${ }^{[10]}$ aimed to assess the impacts associated to the expansion of road US-80 in Longview, Texas. The study focused on changes on land use patterns, commercial activities, land values, and parking availability before, during, and after project implementation. The study relied on field survey to quantify impacts on CAs around the project. Field survey included questions about incomes, customers, workers, 
and parking spots. The study found that land value and businesses sales increased after project completed.

Another study by De Solminihac and Harrison [11] developed a methodology to measure the impact of redesigning US-59 in Houston, Texas. The study used historical data to compare sales of CAs around construction. Also, the study relied on field survey for data collection by interviewing business owners. The sample of this study covered $20 \%$ of CAs around the construction. Field survey questions consisted of four parts:

(1) Historical data about land ownership and activities performances before construction;

(2) Data of activities performance during construction and impacts on sales, employees and incomes;

(3) Data of Activities performance after construction for similar dependent variables;

(4) Interviewing and questioning owners if possible to sale part of the property to projects contractors during $\mathrm{WZ}$, and what factors impacted during construction, and what a strategy suggested to mitigate impacts.

The study found that construction projects on roads had several negative impacts especially on restaurants, furniture stores, and car services. The study emphasized that reducing construction period reduces negative impacts on CAs around construction zones.

In London, a study was conducted by Quddus, Carmel and Bell ${ }^{[12]}$ to analyze impacts of congestion pricing policy on CAs. The study determined a case study of John Lewis Center in Oxford Street. The study included a comparison of weekly sales before and after implementing the congestion pricing. It was found that weekly sales reduced by $8.2 \%$ after the implantation of congestion pricing.
The development consulting group in London published a study in 2003 to determine effects of transforming two ways major street in London CBD to one-way street. The consultant conducted three field surveys to assess the impact, first survey focused on CAs and land ownerships in London CBD. Second field survey included activities on two sides of the street before and after direction changing. Third survey focused on the opinions of general public about directional change and anticipated impacts. The study used descriptive analytical methodology to analyze surveys and interviews ${ }^{[13]}$. Another study identified effects of constructing medians on commercial streets ${ }^{[14]}$. The study evaluated the methodology of Departments of Transportation in Texas to predict economic impacts of median construction. The study has included ten cases in Texas to be evaluated through the following steps:

(1) Selecting several locations with commercial streets;

(2) Identifying characteristics of commercial streets;

(3) Communicating with agencies to collect data about the streets;

(4) Determining CAs located on these streets;

(5) Acquiring the data required about CAs at the determined locations;

(6) Random selection of stores and shops to conduct interviews;

(7) Conducting interviews with stores and shops owners;

(8) Analyzing data and summarizing outcomes.

The study sample included the CAs located on the streets with new median. Distributive analysis has been used to analyze outcomes of the study. It was found that long- 
term constructing medians on commercial streets in Texas doesn't have negative impacts on CAs. Also, the study found that the major negative impacts on CAs were during construction periods. Sales were reduced by $19 \%$ during constructing medians on the streets. There was a high variation of impacts according to project period and type of CAs. Customers of restaurants and retail stores increased after construction of medians. Gas stations and auto repairs had considerable reduction on number of customers. This study emphasized the significance of conducting personal interview with owners rather than mailed questionnaires.

Majority of transportation impact assessment studies focuses on work zone operation. In the Highway Capacity Manual (HCM) $2010^{[15]}$, a model has been created to measure work zone capacity and operational characteristics. Since, the work zone impact on CA on arterials is a major issue, thus this study focuses mainly on work zone issues and effects on CA during work zone lane closure only.

\section{Field Survey}

\subsection{Work Zone Selection and Research Design}

The data of this study has been collected through a field survey that contains 70 questions and covered 201 commercial activities around WZs at two locations. The field survey was completed by interviewing managers and owners. Study sample included all CAs around arterial road closures in Dammam and Khobar. Table 1 summarizes characteristics of the two WZs:

Table 1 shows commonality between WZs locations in Dammam and Khobar. The two WZs were configured by closing all lanes on arterial road and detouring traffic to service, collector, or local roads. The WZ in Khobar covered 2.02 kilometer of the road to build an overpass road and infrastructure maintenance. The work zone in Dammam covered 1.08 of the road to build an overpass with sidewalk maintenance. Lanes have been closed since 2015 when the WZs configuration was completed at two locations. At the end of the study, the WZs were still in the locations. Field survey has been conducted from 20/02/2018 until 20/05/2018 including 70 questions for business managers and owners. The questionnaire has three categories to assess the impact by quantifying changes due to $\mathrm{WZ}$ presence at the location. First category included 20 questions about activity characteristics such as activity, area, number of workers, and number of daily customers. Second category included 35 questions to quantify changes on workers, monthly income, daily customers, and available parking due to WZ presence. The last part included 15 questions of any suggested solutions and recommendations. The study sample included all CAs on both sides of the WZs on arterial roads in Dammam and Khobar. The distance between two WZs is 25 kilometer. Thus, study outcomes and results can be generalized on all WZs in Kingdom of Saudi Arabia with similar characteristics.

Table 1. Work zone characteristics at two study locations.

\begin{tabular}{|c|c|c|c|c|c|}
\hline City & $\begin{array}{c}\text { Location } \\
\text { of work } \\
\text { zone }\end{array}$ & $\begin{array}{c}\text { Number } \\
\text { of closed } \\
\text { lanes }\end{array}$ & $\begin{array}{c}\text { Work } \\
\text { zone } \\
\text { length }\end{array}$ & $\begin{array}{l}\text { Purpose of } \\
\text { work zone }\end{array}$ & $\begin{array}{c}\text { Number of } \\
\text { stores } \\
\text { around } \\
\text { work zone }\end{array}$ \\
\hline Dammam & $\begin{array}{c}\text { Prince } \\
\text { Mohamed } \\
\text { Bin Fahad } \\
\text { road }\end{array}$ & $\begin{array}{l}\text { Complete } \\
\text { closure } \\
\text { (all lanes } \\
\text { closure) }\end{array}$ & $\begin{array}{c}1.08 \\
\text { kilometer }\end{array}$ & $\begin{array}{c}\text { Constructing } \\
\text { overpass } \\
\text { road }\end{array}$ & 76 \\
\hline Khobar & $\begin{array}{c}\text { King } \\
\text { Abdulaziz } \\
\text { Road }\end{array}$ & $\begin{array}{l}\text { Complete } \\
\text { closure } \\
\text { (all lanes } \\
\text { closure) }\end{array}$ & $\begin{array}{c}2.02 \\
\text { kilometer }\end{array}$ & $\begin{array}{c}\text { Constructing } \\
\text { overpass } \\
\text { road }\end{array}$ & 125 \\
\hline \multicolumn{5}{|c|}{ Total } & 201 \\
\hline
\end{tabular}

\subsection{Data Entry and Analysis}

The 201 questionnaires have been entered to Excel Spreadsheet using pre-coding style to analyze data according to owners and managers responses. Frequencies have been 
analyzed for nominal and ordinal rank data. Percentages, means, and standard deviations have been extracted to compare scaled numerical data. The next part presents the results and outcomes in three sections. The first section summarizes CAs characteristics. The second section presents summary of impacts associated to $\mathrm{WZ}$ presence at two locations. The last section provides suggested solutions and recommendations by activities managers and owners to mitigate impacts of WZs.

\section{Analysis of Survey Results}

\subsection{Characteristics of Commercial Activities}

The 201 commercial activities around the WZs in arterial roads at the 2 locations have different characteristics. These CAs differ in:

(1) Activity

(2) Type of firm (Common establishment like banks or small shops)

(3) Area

(4) Customer need (Product or Service)

(5) Location

(6) Marketing policy (Delivery or Customer visit)

(7) Sales approach (Wholesale or retail)

(8) Working hours

(9) Communication modes with customers (Telephone or Internet)

(10) Years of operation at same location

All of these independent variables are associated to increase or decrease the intensity of impact of closing lanes on arterial roads. Activities owners and managers tend to change some of these variables such as working hours in order to mitigate the impact of lane closure. The field survey included 125 CAs around the WZ in Khobar and 76 CAs around Dammam WZ. It was found that $92 \%$ of CAs around the
WZs started before 2015, which is before the closure. Only $8 \%$ of CAs started during 2015 and during lanes closure. The average age of activities and businesses before the closures at the two locations is 9.25 years. The CAs that have been opened during the closure have been excluded from the impact assessment analysis. Thus, the majority of CAs have been included to quantify impacts of the two WZs.

About $55 \%$ of questionnaires have been answered by owners, $43 \%$ by managers, and $2 \%$ by salesmen. The majority of the questionnaires were answered by owners and managers which increase reliability of impact assessment. That is because managers and owners are more aware of changes on income, employee, customers, and parking availability due to WZ presence. About, 94\% of CAs around WZs in Dammam and Khobar are working in retail trade and $6 \%$ on wholesale. The majority of activities (82\%) are productive and $18 \%$ of activities provide services such as cars services and barbers. About $97 \%$ of activities are rented and only 3\% owned such as banking activities. Most of CAs (80\%) are located on ground floor and $20 \%$ of CAs are located on upper levels of buildings. As mentioned earlier, there is a considerable variation in activity types around the WZs on arterial roads in Dammam and Khobar. Table 2 presents the distribution of CAs according to classifications of activities.

The average store area of 201 commercial activities is $372.73 \mathrm{~m}^{2}$. About $76 \%$ of CAs have telephone, web page, and internet service for customers; $13 \%$ have only telephone service; $7 \%$ have only internet and $3 \%$ don't have any communication modes with customers. About $62 \%$ of CAs provide products or services by customers' visit, while $38 \%$ through personal attendance and delivery services. The majority of customers need car parking lots to have access to the stores. About $32 \%$ of workers in CAs are walking to their 
jobs, about $43 \%$ of workers drive to their jobs, while $25 \%$ of them are using private buses. About $19 \%$ of customers reach CAs walking, and $81 \%$ of them drive their own cars to get what they need from the WZs. These percentages indicate that workers and customers need adequate number of parking lots, clear and safe crosswalks and sidewalks.

Table 2. Distribution of commercial activities (CAs).

\begin{tabular}{|l|c|}
\hline Activity Classification & \% \\
\hline Furniture Stores & 17.5 \\
\hline Car Services and Gas Stations & 9.5 \\
\hline Construction Services Offices & 16 \\
\hline Clothing Stores & 13 \\
\hline Advertising Offices & 5.5 \\
\hline Trade and Business & 12.5 \\
\hline Food and Groceries & 6.5 \\
\hline Telecommunication and Technology & 3 \\
\hline Other* & 16.5 \\
\hline
\end{tabular}

*Other commercial activities such as barber shops and coffee shops.

\subsection{Impact of Work Zones in Arterials Roads on Commercial Activities}

The variations of characteristics of commercial activities around WZs in Dammam and Khobar are reflected on the various intensity of impacts at the same location.

\subsubsection{Work zone impacts on number of workers}

It was found that, $46 \%$ of CAs had a reduction on number of workers and employees during WZ presence. Only 5\% of CAs had an increase on number of workers, and $49 \%$ doesn't have change on number of workers. The average number of workers before the presence of the WZ is 9 workers per business. While the average number of workers during the $\mathrm{WZ}$ presence is 7 workers per business. The work zones impacted commercial services by $20 \%$ reduction in the number of workers. Table 3 shows the mean and standard deviation of percentage reduction on number of workers:
Table 3. Impact of work zones on number of workers in commercial activities.

\begin{tabular}{|c|c|c|c|}
\hline $\begin{array}{c}\text { Number of } \\
\text { worker before } \\
\text { lanes closure }\end{array}$ & $\begin{array}{c}\text { Number of } \\
\text { workers during } \\
\text { lanes closure }\end{array}$ & $\begin{array}{c}\text { Mean of \% } \\
\text { reduction to } \\
\text { number of } \\
\text { workers }\end{array}$ & STD \\
\hline 9 & 7 & 0.22 & 0.25 \\
\hline
\end{tabular}

Table 3 shows that average square root of means are higher than average reduction. The variation of reduction on number of workers is related to the variation of characteristics of CAs. Commercial activities with high number of workers have higher reduction to number of workers and employee during the WZs. The owners and managers of CAs around the WZs tend to reduce number of workers in order to reduce costs. Reduction on monthly cost assists in mitigating WZs effect on sales during lanes closure. Table 4 includes the distribution of $46 \%$ reduction of workers by activity:

Table 4. Percentage of workers reduction by activity.

\begin{tabular}{|l|c|}
\hline Activity & \% of activity \\
\hline Restaurants & $14 \%$ \\
\hline Furniture Stores & $5 \%$ \\
\hline Car Rentals & $4 \%$ \\
\hline Travel Agencies & $3 \%$ \\
\hline Groceries and Tailors & $2 \%$ \\
\hline Others* & $18 \%$ \\
\hline
\end{tabular}

* Reduction on number of workers from different activities

Table 4 shows that the most impacted activity on number of workers are restaurants (14\%). However, travel agencies had the most intense impact on number of workers by $37 \%$ reduction. Managers and owners of CAs revealed that they gave their workers unpayable open vacation until the end of lane closures period. Majority of workers traveled to their homeland in order to reduce their cost of living (by saving the rent for example).

\subsubsection{Work zones impacts on number of daily customers}

The number of daily customers includes activity visitors whether they are regular customers or spontaneous consumers. It was 
found that $95 \%$ of CAs had a reduction on number of customers during the $\mathrm{WZ}$ presence. About 3\% of CAs don't have reduction, and $2 \%$ had an increase on number of daily customers during the $\mathrm{WZ}$ presence. This minor percentage of CAs which had an increase in number of daily customers during WZ have used social media applications and internet for marketing. Average number of daily customers before WZ presence was 85 customers per day. While average number of daily customers during the WZ presence is 55 customers per day. Thus, average percentage of reduction on number of daily customers is $35 \%$. Table 5 shows mean and standard deviation of percentages reduction of daily customers.

Table 5. Work zone impact on number of daily customers.

\begin{tabular}{|c|c|c|c|}
\hline $\begin{array}{c}\text { Number of daily } \\
\text { customers } \\
\text { before lanes } \\
\text { closure }\end{array}$ & $\begin{array}{c}\text { Number of } \\
\text { daily } \\
\text { customers } \\
\text { during lanes } \\
\text { closure }\end{array}$ & $\begin{array}{c}\text { Mean of \% } \\
\text { reduction to } \\
\text { number of daily } \\
\text { customers }\end{array}$ & STD \\
\hline 85 & 55 & 0.35 & 0.28 \\
\hline
\end{tabular}

Table 5 shows high variation of WZ impact on number of daily customers. This variation related to variation on characteristics of CAs associated to type of product or service provided, length of relationship with the customers, and market competition. The customers are highly willing to get their requirements of goods and services from accessible CAs.

\subsubsection{Work zone impacts on regular customers and spontaneous consumers}

The field survey included questions about the impact of $\mathrm{WZ}$ on regular and spontaneous consumers. Regular customers prefer to deal with similar CAs every time they need goods or services. The relationship between regular customers and CAs is long and existed before WZ presence. Spontaneous consumers are customers walking around CAs for shopping without looking for a certain goods or specific services. Spontaneous consumers walk around for shopping by reading signs and panels of CAs. The major difference between spontaneous consumers and regular customers is the intent of shopping. Spontaneous consumers are walking around CAs and buying from commercial stores randomly based on needs. While regular customers are traveling for shopping from specific stores, impact of WZ on visibility of CAs signs affects the number of spontaneous consumers.

It was found that $95 \%$ of CAs around WZ had a reduction on number of regular customers. Only 3\% of CAs does not have change and $2 \%$ had an increase in number of regular customers. This minor percentage of shops that had an increase extended the working hours and applied delivery service during the $\mathrm{WZ}$ presence. Also, it was found that average reduction on number of regular customers of CAs is $33 \%$. The average number of regular customers was 54 customers/activity/day before $\mathrm{WZ}$ presence and 36 customers/activity/day during WZ presence. The study also found that $82 \%$ of CAs had a reduction on spontaneous consumers, while $7 \%$ of CAs do not have change in number of spontaneous consumers, and $5 \%$ had an increase during $\mathrm{WZ}$ presence. Average number of spontaneous consumers to CAs before the WZ presence is 32 customers per day. Average number of spontaneous consumers during the $\mathrm{WZ}$ presence is 18 customers per day, and average reduction on spontaneous consumers is $22 \%$. Table 6 shows mean and standard deviation of reduction on regular customers and spontaneous consumers.

There is 0.24 and 0.21 variation between average square root of means of regular customers and spontaneous consumers respectively. This variation is related to the variation of characteristics of CAs between productive and services, providing the service by customer presence or delivery, and the difference in areas and locations. 
Table 6. Impact of work zone presence on regular customers and spontaneous consumers.

\begin{tabular}{|c|c|c|c|c|}
\hline $\begin{array}{c}\text { Type of } \\
\text { Customers }\end{array}$ & $\begin{array}{c}\text { Average } \\
\text { Before } \\
\text { Work } \\
\text { Zone }\end{array}$ & $\begin{array}{c}\text { Average } \\
\text { During } \\
\text { Work } \\
\text { Zone }\end{array}$ & $\begin{array}{c}\text { Average } \\
\text { \% } \\
\text { Reduction }\end{array}$ & $\begin{array}{c}\text { STD of \% } \\
\text { Reduction }\end{array}$ \\
\hline $\begin{array}{c}\text { Regular } \\
\text { Customers }\end{array}$ & 54 & 36 & 0.33 & 0.24 \\
\hline $\begin{array}{c}\text { spontaneous } \\
\text { consumers }\end{array}$ & 23 & 18 & 0.22 & 0.21 \\
\hline
\end{tabular}

\subsubsection{Work zone impact on daily sales}

It was found that average of change of daily sales is similar to percentages change on number of daily customers, which makes sense. According to the questionnaire respondents, the average daily sales before WZ presence was 15000 Saudi Riyal (SAR). The average daily sales during WZ presence on arterial road was 10000 SAR. Thus, average reduction of daily sales is $33 \%$ as an impact of WZ presence. About $93 \%$ of CAs had a reduction in daily sales. Only $4 \%$ of CAs had an increase in daily sales by extending working hours, and 3\% doesn't have change. Table 7 presents mean and standard deviation of daily sales before and during $\mathrm{WZ}$ presence.

Table 7. Impact assessment of work zone on daily sales.

\begin{tabular}{|c|c|c|c|}
\hline $\begin{array}{c}\text { Average daily } \\
\text { sales before } \\
\text { lanes closure } \\
\text { (Saudi Riyal) }\end{array}$ & $\begin{array}{c}\text { Average daily } \\
\text { sales during } \\
\text { lanes closure } \\
\text { (Saudi Riyal) }\end{array}$ & $\begin{array}{c}\text { Mean of \% } \\
\text { reduction of } \\
\text { daily sales }\end{array}$ & STD \\
\hline 15000 & 10000 & 0.33 & 0.32 \\
\hline
\end{tabular}

Table 7 shows that square root of means almost equals the mean that is referred to solutions applied by CAs to mitigate the impact as possible. Minor percentage of CAs around the WZs extended the working hours until 2 AM, while regular working hours are from $10 \mathrm{AM}$ to $12 \mathrm{AM}$. Other CAs provided delivery services to customers by telephone, websites, and social media applications. In addition, variations of characteristics of CAs are correlated to variation of daily sales.

\subsubsection{Work zone impact on monthly rent}

It was found that $25 \%$ of CAs around two WZs had a reduction in monthly rent from properties owners. Majority of CAs (56\%) doesn't have change on monthly. Only $19 \%$ of CAs had an increase in monthly rent from properties owners for enhancing mobility and accessibility after construction. The mean of monthly rent of CAs around two WZs is 166000 SAR. The standard deviation of monthly rents of CAs is 163100 SAR. The variation and differences in areas, activities, and locations of CAs increased the variations in monthly rent between CAs.

\subsubsection{Work zone impact on parking availability}

The lanes closures at two WZs caused a $20 \%$ reduction of parking availability in $31 \%$ of CAs. Only $2 \%$ of CAs had an increase in available parking during lanes closure. While $67 \%$ of CAs does not have change on number of parking available, the average parking available for CAs before $\mathrm{WZ}$ presence was 5 lots. While average parking available during WZ presence was 4 parking lots. About 13\% of CAs owners and managers complained about the length of time to find a parking spot around their activity location. A separate study has to be conducted to measure the impact of $\mathrm{WZ}$ presence in arterial roads on travel time. The impact of $\mathrm{WZ}$ presence on parking availability is not significant. But, CAs that complained about parking reduction had a severe impact on parking availability. According to field survey, the $18 \%$ reduction on available parking is major factor associated to impacts on sales, rent, customers, and income. The reason of low reduction on available parking is that second location of WZ in Dammam included a shopping mall. The CAs inside the mall did not have changes in the number of parking lots available because they had underground parking lot. The number of CAs inside the mall cover $31 \%$ of 
$67 \%$ that did not have changes on parking availability. Table 8 shows the mean and standard deviation of reduction in parking availability at two WZs.

Table 8. Work zone impact on parking availability of commercial activities.

\begin{tabular}{|c|c|c|c|}
\hline $\begin{array}{c}\text { Average } \\
\text { Parking Spots } \\
\text { Available } \\
\text { Before the } \\
\text { Closure }\end{array}$ & $\begin{array}{c}\text { Average } \\
\text { Parking Spots } \\
\text { Available } \\
\text { During the } \\
\text { Closure }\end{array}$ & $\begin{array}{c}\text { Mean of \% } \\
\text { reduction of } \\
\text { Parking Spots }\end{array}$ & STD \\
\hline 5 & 4 & 0.20 & 0.35 \\
\hline
\end{tabular}

Table 8 shows that average square root of means is higher than actual mean of number of parking lots available. This is related to the variation in locations of CAs which is associated to side parking availability. The majority of CAs in Khobar complained about parking availability. The minor percentage was in Dammam complained about a reduction in parking availability, because the majority of CAs in Dammam has available underground parking lots in shopping malls.

\subsubsection{Work zone impact on infrastructure services}

The field survey included comments of issues of infrastructure services during WZ presence. It was found that $5 \%$ of CAs had electricity and water supply issues during WZ presence. About $4 \%$ of managers and owners submitted official complain letters to The Eastern Province Municipality. About $20 \%$ of the owners were looking for new locations to move their businesses. About 32\% of CAs were satisfied with the impacts of WZs in general and $68 \%$ were not satisfied.

\subsubsection{A comparison of work zone impact on different variables at 2 locations}

The data of impact of WZ at the two locations in Dammam and Al-Khobar is not normally distributed. Student T-test or Z test for statistical comparison between the two locations or before and during WZ cannot be conducted. The data has to be normally distributed in order to conduct statistical comparison to show significant difference. As mentioned earlier, variation of characteristics of CAs are associated to different percentages of WZ impacts on different aspects. Thus, the resulted distributions of percentages are not normally distributed to conduct justifiable statistical comparison. However, Table 9 presents the average percentage of WZ impacts on different aspects at each location separately:

Table 9. Work zone impact on commercial activities for each location.

\begin{tabular}{|c|c|c|c|c|c|}
\hline 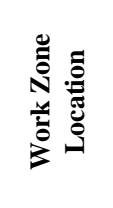 & 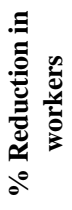 & 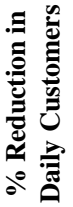 & 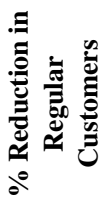 & 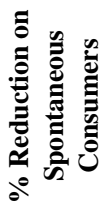 & 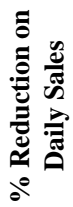 \\
\hline $\begin{array}{c}\text { Location } \\
(1)^{*}\end{array}$ & $22 \%$ & $36 \%$ & $35 \%$ & $24 \%$ & $29 \%$ \\
\hline $\begin{array}{c}\text { Location } \\
(2)^{*}\end{array}$ & $22 \%$ & $34 \%$ & $30 \%$ & $20 \%$ & $36 \%$ \\
\hline
\end{tabular}

*Location (1) is the work zone in Al-Khobar on King Abdul-Aziz Road.

*Location (2) is the work zone in Dammam on Prince Mohamed Bin Fahad road.

Table 9 showed that there is no difference of WZ impact on workers between the 2 locations, while there are small differences between percentages of reduction in sales and customers. In Al-Khobar, the highest impact was on number of customers, whereas in Dammam the highest impact was on sales. Thus, findings and results of two WZ locations are mutual and can be generalized to WZ impact on CAs on arterial roads.

\subsection{Degree of Satisfaction of Activities Owners and Managers about Work Zone Presence}

This part of field survey included 21 points and issues to reflect owners and managers opinions and degree of satisfaction about various issues of $\mathrm{WZ}$ presence. The owners and managers had to answer with highly agree, agree, don't know, don't agree, 
and highly don't agree. Table 10 presents the distribution of responses regarding different issues.

Table 10 presented distribution of owners and managers responses regarding several issues of WZs presence. According to their responses, the WZs improved walkability around CAs on sidewalks. But at the same time, WZs did not improve walking and shopping because only $19 \%$ of customers shop by walking. Closing lanes on arterials for WZs configuration reduced accessibility of trucks and heavy vehicles for loading and unloading. Supply of goods to CAs is fundamental for business and continuity of commercial activity. Rents of CAs around WZ will increase as a result of enhancing mobility and accessibility after WZ removal and completion of construction project. There was an increase in air and noise pollution around the WZs and increase in number and severity of traffic accidents. Reduction of speed at WZs enhanced visibility to signs of CAs on both sides of the road, but it increased traffic accidents at the same time.

\subsection{Owners Suggestions to Mitigate Work Zones Impacts}

The field Survey included multiple suggested solutions to be recommended by owners and managers of CAs. Table 11 shows distribution of solutions to reduce impacts of WZs on arterials:

Table 11 presented public agreement on several suggested solutions by activities owners and managers except extending working hours. Several CAs such as banks don't have ability and authority to extend working hours. The Saudi Authority of Currency determines proper working hours of commercial banks. Municipalities of Saudi Arabia have to implement plans and strategies of multiple solutions from Table 11 to reduce WZs impacts.

Table 10. Percentages distribution of owners and managers responses regarding work zones impacts.

\begin{tabular}{|c|c|c|c|c|c|}
\hline Work Zone Impacts & $\begin{array}{c}\text { Total } \\
\text { Agree } \\
\end{array}$ & Agree & Unknown & Disagree & $\begin{array}{c}\text { Total } \\
\text { Disagree }\end{array}$ \\
\hline The work zone encouraged business and trade & $0 \%$ & $2 \%$ & $2 \%$ & $93 \%$ & $3 \%$ \\
\hline The work zone enhanced customers accessibility to commercial stores & $0 \%$ & $2 \%$ & $0 \%$ & $95 \%$ & $3 \%$ \\
\hline The work zone increased ease in loading and unloading of goods & $0 \%$ & $0 \%$ & $3 \%$ & $96 \%$ & $1 \%$ \\
\hline The work zone increased number of shoppers & $0 \%$ & $0 \%$ & $1 \%$ & $96 \%$ & $3 \%$ \\
\hline The work zone increased daily and monthly sales & $1 \%$ & $1 \%$ & $1 \%$ & $94 \%$ & $3 \%$ \\
\hline $\begin{array}{l}\text { The work zone increased noise pollution issued from traffic and on } \\
\text { road work }\end{array}$ & $62 \%$ & $34 \%$ & $2 \%$ & $1 \%$ & $1 \%$ \\
\hline The work zone increased air pollution issued from traffic and on road work & $66 \%$ & $31 \%$ & $2 \%$ & $1 \%$ & $0 \%$ \\
\hline The work zone enhanced visibility of commercial signs & $1 \%$ & $45 \%$ & $16 \%$ & $36 \%$ & $2 \%$ \\
\hline The work zone increased parking availability & $0 \%$ & $0 \%$ & $7 \%$ & $91 \%$ & $2 \%$ \\
\hline The work zone enhanced visibility of traffic signs and signals & $0 \%$ & $2 \%$ & $60 \%$ & $36 \%$ & $2 \%$ \\
\hline The work zone enhanced workers accessibility to commercial stores & $1 \%$ & $2 \%$ & $73 \%$ & $21 \%$ & $3 \%$ \\
\hline The work zone increased traffic accidents on arterial road & $15 \%$ & $74 \%$ & $10 \%$ & $1 \%$ & $0 \%$ \\
\hline The work zone increased accidents severity occurred on arterial road & $16 \%$ & $76 \%$ & $7 \%$ & $1 \%$ & $0 \%$ \\
\hline The work zone increased renting commercial stores around the road & $2 \%$ & $18 \%$ & $26 \%$ & $52 \%$ & $2 \%$ \\
\hline The work zone increased the price of renting commercial stores & $26 \%$ & $66 \%$ & $4 \%$ & $2 \%$ & $2 \%$ \\
\hline The work zone encouraged crossing the arterial road from both sides & $4 \%$ & $81 \%$ & $6 \%$ & $8 \%$ & $1 \%$ \\
\hline The work zone increased comfort of walking on sidewalks & $3 \%$ & $88 \%$ & $6 \%$ & $2 \%$ & $1 \%$ \\
\hline The work zone increased shopping by walking on sidewalks & $1 \%$ & $4 \%$ & $10 \%$ & $83 \%$ & $2 \%$ \\
\hline The work zone encouraged changing recent location of commercial stores & $58 \%$ & $39 \%$ & $1 \%$ & $2 \%$ & $0 \%$ \\
\hline The work zone enhanced mobility and accessibility of goods to stores & $0 \%$ & $1 \%$ & $4 \%$ & $92 \%$ & $3 \%$ \\
\hline The work zone contributed in changing types of activities around the road & $58 \%$ & $31 \%$ & $7 \%$ & $3 \%$ & $1 \%$ \\
\hline
\end{tabular}


Table 11. Suggested solutions recommended by business managers and owners to mitigate work zones impacts.

\begin{tabular}{|c|c|c|c|c|c|}
\hline Recommended Solutions & $\begin{array}{r}\text { Total } \\
\text { Agree }\end{array}$ & Agree & Unknown & Disagree & Total Disagree \\
\hline $\begin{array}{l}\text { Announce and inform stores with adequate time period } \\
\text { before closure }\end{array}$ & $87 \%$ & $12 \%$ & $1 \%$ & $0 \%$ & $0 \%$ \\
\hline Create alternative side routes on local roads & $84 \%$ & $16 \%$ & $0 \%$ & $0 \%$ & $0 \%$ \\
\hline Increase number of exists to local roads & $16 \%$ & $84 \%$ & $0 \%$ & $0 \%$ & $0 \%$ \\
\hline Increase number of entrances to land use & $15 \%$ & $85 \%$ & $1 \%$ & $0 \%$ & $0 \%$ \\
\hline Increase width of sidewalks around stores & $19 \%$ & $30 \%$ & $50 \%$ & $1 \%$ & $0 \%$ \\
\hline Provide pedestrian bridges from side to side & $75 \%$ & $24 \%$ & $1 \%$ & $0 \%$ & $0 \%$ \\
\hline Provide financial compensations to owners & $79 \%$ & $17 \%$ & $4 \%$ & $0 \%$ & $0 \%$ \\
\hline Cancelation of governmental fees & $82 \%$ & $14 \%$ & $4 \%$ & $0 \%$ & $1 \%$ \\
\hline Allowance to extend working hours & $7 \%$ & $24 \%$ & $50 \%$ & $19 \%$ & $0 \%$ \\
\hline Increase number of parking spots around & $84 \%$ & $15 \%$ & $1 \%$ & $0 \%$ & $0 \%$ \\
\hline Reduce duration of projects implementation & $74 \%$ & $17 \%$ & $8 \%$ & $1 \%$ & $0 \%$ \\
\hline Pay stores rents during lanes closure & $75 \%$ & $14 \%$ & $10 \%$ & $1 \%$ & $0 \%$ \\
\hline Provide public transportation services & $77 \%$ & $22 \%$ & $1 \%$ & $0 \%$ & $0 \%$ \\
\hline Widening service road around work zones & $80 \%$ & $19 \%$ & $1 \%$ & $0 \%$ & $0 \%$ \\
\hline Treat Transportation network on cities level & $77 \%$ & $23 \%$ & $0 \%$ & $0 \%$ & $0 \%$ \\
\hline
\end{tabular}

\section{Summary of Findings}

This study aimed to assesses the impacts of long-term WZs in arterial roads on CAs in Dammam Metropolitan area. The literature review highlighted some positive and negative impacts as well as some mitigation measures for the negative ones.

The Federal Highway Administration in the USA found that closing lanes to occupy dedicated WZ has many positive impacts. It reduced transportation projects periods from $70 \%$ to $80 \%$. Also, lane closures enhance traffic safety for users and workers and increase workers productivity by occupying the required areas for work on the roadway, (8). However, the same study found that activities around the WZ are negatively impacted during lane closures. This is because of the WZ configuration reduces accessibility and mobility around working areas. Thus, regular and walking customers are looking for other accessible areas for shopping ${ }^{[8]}$.

Other studies underlined the WZs negative impacts as well. Boarnet study ${ }^{[9]}$ about Los Anglos found significant negative impacts on retail and wholesale activities related to delays in freight delivery. De Solminihac and Harrison [11] found that construction projects on roads had several negative impacts especially on restaurants, furniture stores, and car services. Also, the development consulting group in London conducted a study to determine effects of transforming two ways major street in London CBD to one-way street. The study found that the major negative impacts on CAs were during construction periods. Sales were reduced by $19 \%$ during this period.

The reviewed literature proposed several mitigation measures. The study of (US-101) closure that included assessing economic impacts of arterial road closure connecting California with surrounding areas in United States of America, produced impact assessment model of tourism generation, production, and attraction from tourism facilities on the road. The study provided suggested alternative route of the closure ${ }^{[6]}$. De Solminihac and Harrison ${ }^{[11]}$ emphasized that reducing construction period reduces negative impacts on CAs around construction zones. 
Also, providing financial support directly to affected society could be one of the solutions. However, the literature shows that it is not legally simple to implement direct compensation to businesses in WZs. If the businesses were notified of the road closure and the announced closure dates were respected, businesses are not eligible for financial compensations ${ }^{[2]}$. Yet, authorities manage to find ways to provide affected businesses with financial compensation ${ }^{[2]}$.

The present study about the DMA, found that closing lanes on arterial roads for WZ configuration to implement transportation projects negatively affects local CAs. After completion, transportation projects will improve mobility and accessibility on the city level. But at the same time, during implementing the projects, WZs affect negatively local activities, mobility, and accessibility. Impacts of WZs dedicated for transportation projects which require occupying areas on arterial roads are:

(1) $22 \%$ reduction of workers numbers in CAs;

(2) $35 \%$ reduction of daily customers visiting CAs;

(3) $33 \%$ reduction of regular customers;

(4) $22 \%$ reduction of passing (walkingby) shoppers;

(5) $33 \%$ reduction of daily sales of CAs;

(6) $20 \%$ reduction of available parking lots around CAs;

(7) Reduction of mobility and accessibility of freight transportation;

(8) Reduction of visibility and traffic safety and increase in air and noise pollution;

(9) It was found that restaurants and travel agencies are the most affected activity by WZ presence, while banks are the least affected. Especially that banks are common firms not a productive providing services to customers.

However, WZs dedicated for transportation projects on arterial roads have positive impacts. Indeed, WZs enhance walkability on sidewalks and crosswalk at the area of lanes closure. Detour traffic movement at the WZ is associated to traffic speed reduction and increases walkability. Plans, policies, and strategies of multiple suggested solutions in Table 11 assist in mitigating the negative impacts of WZs. The variations of characteristics of CAs increase difficulty of calibrating prediction model of WZs impacts. Additional variables such as length of relation between customers and commercial activity have to be considered to calibrate $\mathrm{WZ}$ model. Correlations between WZ impacts on various variables and characteristics of CAs are not confirmed.

In future research, authors are interested in testing the impact of increasing speed on arterials, due to transportation construction and maintenance projects, in Kingdom of Saudi Arabia. The main hypothesis of this study is that increasing operational speed on arterial roads reduces visibility of commercial signs of CAs and thus reduces customers; sales; and income.

Moreover, authors intend to conduct several future studies to test further related issues. In one of the studies, authors will measure impact of $\mathrm{WZ}$ presence in arterial roads on travel time. In another study, authors will assess the impact of change on road way configuration and operational characteristics, such as operational speed, level of services and capacity.

\section{Data Availability Statement}

The author confirms that the data supporting the findings of this study are available within its supplementary materials. 
The data of this study is available in Excel Spreadsheet on four sheets; first sheet is the characteristics of commercial activities. The second is the WZ impact presented by percentages change on workers, customers, sales, and parking. The third sheet includes opinions of owners and managers regarding several issues of WZ. And last sheet contains solutions and recommendations to mitigate impacts of WZ presence.

\section{References}

[1] Project Agency in Eastern Province Municipality Amanah (2013). Operation and maintenance projects report. Dammam, Saudi Arabia: Project Agency in Eastern Province Municipality, Amanah.

[2] Safe Harbor Working Group and MainStreet Business Assistance Program (2014). Mitigation of Transportation Construction Impacts on Business, Tucson.

[3] Transport Appraisal and Strategic Modelling (TASM) Division (2018). TAG UNIT A2.1. Wider Economic Impacts Appraisal. London: Department for Transport.

[4] Forkenbrock, D. J. and Weisbrod, G. (2001). NCHRP Report 456. Guidebook for Assessing the Social and Economic Effects of Transportation Projects, Washington, D.C., National Academy Press.

[5] Fayman, S., Metge, P., Spiekemann, K., Wegener, M., Flowerdew, T. and Williams, I. (1995). The regional impact of the channel tunnel, Qualitative and quantitative analysis. European Planning Studies., III (3).

[6] California Department of Transportation (2015).
Economic Impact of US-101 Closure, 2015..

[7] Auckland Council (2017). The Congestion Question. Could Road Pricing Improve Auckland's Traffic? Auckland.

[8] Forkenbrock, D. J., Benshoff, S. and Wiesbrod, G. E. (2001). Assessing the Social and Economic Effects of Transportation Projects. WASHINGTON, D.C.: National Cooperative Highway Research Program, Transportation Research Board, National Research Council. National Academy Press.

[9] Boarnet, M. G. (1996) The Direct and Indirect Economic Effects of Transportation Infrastructure. Working Paper. Irvine: University of California Institute of Transportation Studies.

[10] Buffington, J. L. and Wildenthal, M. T. (1993). Estimated Impact of Widening U.S. Highway 80 (Marshall Avenue) in Longview, Texas. Transportation Research Record 1450: pp. 59-64.

[11] De Solminihac, H. and Harrison, R. (1993). Analyzing Effects of Highway Rehabilitation on Businesses. Transportation Research Record 1395: pp. 137-143.

[12] Quddus, M.A., Carmel, A. and Bell, M.G.H. (2007). The impact of the congestion charge on retail: the London experience. Journal of Transport Economics and Policy, 41(1): 113-133.

[13] South Street Campus Lands Development. City of London (2013). Transportation Impact Assessment. London.

[14] Eisele, W. L. and Frawley, W. E. (2000). A Methodology for Determining Economic Impacts of Raised Median. Research Project Report. Texas Transportation Institute, Texas, USA.

[15] Missouri Department of Transportation (2010). Highway Capacity Manual (HCN). Washington: Transportation Research Board. 
دراسة تأثثر إغلاقات الطرق الثريانية على الاستخدام التجاري في حاضرة الدمام

نواف محمد الثبيبي و حاتم طومان عبد الحميد"

قسم التخطيط الحضري والإقليمي، كلية الععارة والتخطبط، جامعة الإمام عبدالرحمن بن فيصل، الدمام، الملكتة العربية السعودية htabdelhamid@iau.edu.sa*

المستخلص. تهدف هذه الدراسة إلى نقدير التأثير الناتج عن إغلاقات الطرق الثريانية في حاضرة الدمام على استخدامات الأراضي التجارية. وتركز الدراسة على حالثين دراسيتين تمثل

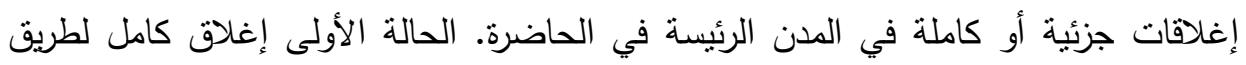

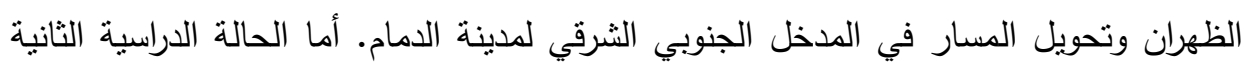

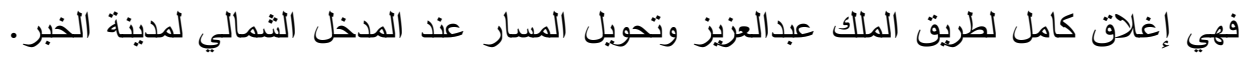

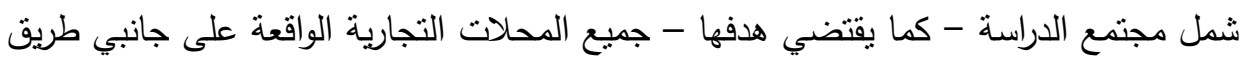
الظهران في الدمام وطريق الملك عبدالعزيز في الخبر، سواء في الأدوار الأرضية أو المتكررة.

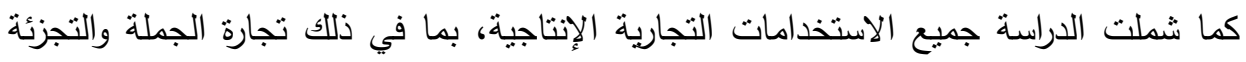

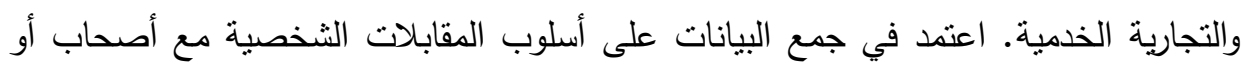

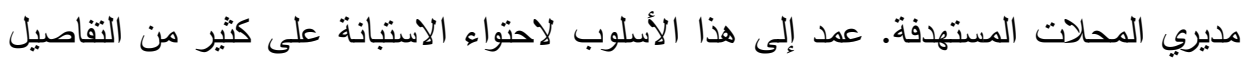

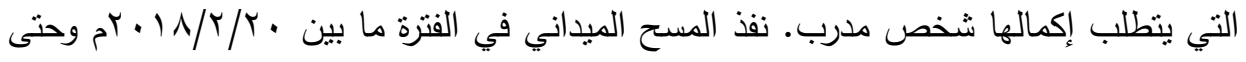

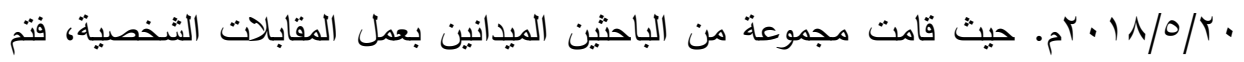

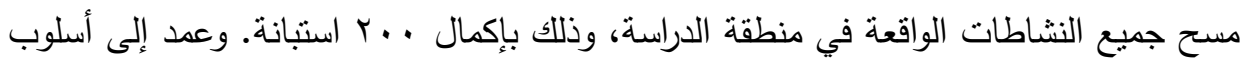

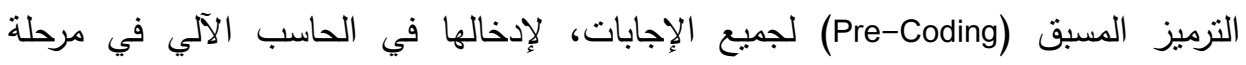

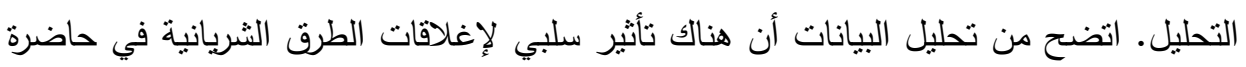

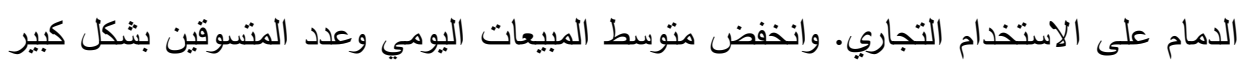
لصعوبة الوصولية، وعدم توفر المواقف بالذات خلال فترة الإغلاقات. كلمات مفتاحية: إغلاقات الطرق الثريانية، الاستخدام التجاري، حاضرة الدمام، المملكة العربية

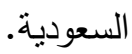

